\title{
Erasing the Homunculus as an Ongoing Mission: A Reply to the Commentaries
}

\author{
James R. Schmidt ${ }^{1}$, Baptist Liefooghe ${ }^{2}$, and Jan De Houwer ${ }^{3}$ \\ ${ }^{1}$ LEAD-CNRS UMR 5022, Université Bourgogne Franche-Comté (UBFC), FR \\ 2 Department of Psychology, Utrecht University, NL \\ ${ }^{3}$ Department of Experimental Clinical and Health Psychology, Ghent University, BE \\ Corresponding author: James R. Schmidt (james.schmidt@ubfc.fr)
}

In our recent article (Schmidt, Liefooghe, \& De Houwer, 2020, this volume), we presented an adaptation of the Parallel Episodic Processing (PEP) model for simulating instruction following and task-switching behaviour. In this paper, we respond to five commentaries on our article: Monsell \& McLaren (2020), Koch \& Lavric (2020), Meiran (2020), Longman (2020), and Pfeuffer (2020). The commentaries discuss potential future modelling goals, deeper reflections on cognitive control, and some potential challenges for our theoretical perspective and associated model. We focus primarily on the latter. In particular, we clarify that we (a) acknowledge the role of cognitive control in task switching, and (b) are arguing that certain task-switching effects do not serve as a good measure of said cognitive control. We also discuss some ambiguities in terminological uses (e.g., the meaning of "task-set reconfiguration"), along with some future experimental and modelling research directions.

Keywords: computational modelling; neural networks; episodic memory; binding; switch costs; feature integration; task-rule congruency; instruction implementation; goals

\section{Smash the Control Machine?}

Koch and Lavric (2020) suggest that we "are on a sort of 'mission' against cognitive control of task-set[s]". This is untrue. As Longman (2020) reiterates well, one of our aims was to implement some executive processes in a less ambiguous (or "homuncular") fashion (e.g., instead of referring to vague concepts like "task parameters" or "control settings"). This is what we refer to when we talk about "erasing the homunculus", which is a quest shared by many researchers (Frings et al., 2020; Hommel \& Colzato, 2015; Logan, 1990; Monsell \& Driver, 2000; Verbruggen, McLaren, \& Chambers, 2014). Within this ongoing mission of erasing the homunculus, we extended the Parallel Episodic Processing (PEP) model (Schmidt et al., 2020) by assuming that participants retrieve goals from exemplar memory on the basis of instructed cue-goal pairings (cf., Schneider \& Logan, 2005).

Hypothesized influences of cognitive control (i.e., processes relying on the executive system) on the size of the switch cost also does not argue against our perspective. For example, children with attention deficit produce a reduced switch cost, which is in turn reduced to normal with methylphenidate treatment (e.g., Kramer, Cepeda, \& Cepeda, 2001). Meiran (2020) notes that impaired attentional control (a process relying on the executive) may lead to a larger switch cost because attention deficit children rely more on episodic memory, exaggerating the binding biases. This explanation is consistent with our message: cognitive control is important, but the switch cost itself is primarily due to binding biases. In this sense, we are sympathetic with the view of Meiran that automatic effects are often a "side effect" of control (see Meiran, Liefooghe, \& De Houwer, 2017).

Similarly, the observation that switch costs are absent when participants are given compound cue instructions (i.e., rather than abstract task instructions; Dreisbach, Goschke, \& Haider, 2006, 2007; Forrest, Monsell, \& McLaren, 2014), can also be accommodated by PEP by assuming that executive processes impact on the operation of memory and binding processes. In this case, the goal of the participant is different and within PEP this could be implemented by simply coding the cue-target-response combinations into the instructions, 
rather than cue-goal and decision-response combinations. The PEP model currently does not implement compound-cue target instructions, but potentially could (also potentially relevant for some findings in the contingency learning literature; e.g., Mordkoff \& Halterman, 2008).

Longman (2020) discusses a series of eye tracking experiments in which evidence of attentional inertia is observed (e.g., Longman, Lavric, Munteanu, \& Monsell, 2014; Longman, Lavric, \& Monsell, 2016, 2017). The cues indicated to participants not only which task to perform, but also which spatial location the target is in. Participants showed not only a standard switch cost, but also a bias to reattend the last target location on task switches. Though we did not consider spatial attention and these eye-tracking studies did not fully control for binding biases, this attentional-inertia effect is not inconsistent with the goal-inertia of the PEP model. That such attentional-inertia effects can be eliminated by using explicit location cues can also be implemented in our model, as simple retrieval of "where to look" on the basis of the cue likely can be completed much faster than "what task to do and in what location is the target for said task". What is clear, of course, is that the PEP model has not (yet) specified the implementation of task goals other than "do Task X", which is an interesting direction for future modelling research.

\section{Direct Causes}

We assume (and model) executive influences on behaviour, but our primary goal was to explore to what extent certain key phenomena (effects) are a direct result of and, more importantly, could provide an index of such control. Whether cognitive control is involved in a general way in a paradigm that produces a specific experimental effect and whether this experimental effect is a direct proxy of a cognitive-control operation are two very different questions. With respect to task switching, we are positive that cognitive control is involved when switching tasks. In PEP, this involvement exists, but is (at least primarily) not directly responsible for most of what the model produces. Task-set reconfiguration (TSR) or task-set inertia (TSI) accounts, on the other hand, are driven by the assumption that changing tasks requires the (re)configuration of a task-set (similar to our account), which induces a switch cost (dissimilar to our account). Traditionally, the switch cost is thus considered as the result of TSR, TSI, or both, which are thus specific cognitive operations involved in the change of task-sets.

Of course, it has been long appreciated that other biases exist and that the switch cost is therefore not a process-pure measure of (re)configuration (e.g., Arrington \& Logan, 2004; Logan \& Bundesen, 2003, 2004; Logan \& Schneider, 2006; Monsell \& Mizon, 2006; Schneider \& Logan, 2005), which is echoed by Koch and Lavric (2020) and Monsell and McLaren (2020). However, part of our endeavour (initially in Schmidt \& Liefooghe, 2016; and subsequently in Schmidt et al., 2020) was to assess the joint contribution of these biases to the switch cost (i.e., controlling for everything at once). This joint contribution is substantial and, in our view, most of the switch cost is explained by biases not directly related to the change in the task. In addition, we used a best-case design, where the tasks were set up to produce the largest possible switch cost (e.g., short CTIs, arbitrary cues, etc.). However, although we provided the best possible conditions for TSR or TSI to magnify the switch cost (e.g., when no preparation is possible and proactive interference is maximal), the variance left unexplained by generic binding processes was small.

The systematic biases that we and others have observed in the switch cost raise some important questions. Manipulations that increase (or decrease) the size of the switch cost may actually be influencing simpler binding processes rather than the cost of switching tasks. Similar ambiguities have emerged in the attentional control literature (for a consensus paper, see Braem et al., 2019). Generic executive processes may play a role in task switching, but our work presents a new perspective on executive control and highlights other biases that may have more explanatory power in explaining task switching phenomena than previously assumed.

\section{Ambiguity in Definitions}

One point of disagreement with our article seems to be how to describe the functioning of the PEP model conceptually. Traditionally, TSR was defined as a discrete step process that occurs, not necessarily completely, before stimulus processing (e.g., Meiran, 1996; Rogers \& Monsell, 1995). TSI was proposed as an alternative (e.g., Allport, Styles, \& Hsieh, 1994; Gilbert \& Shallice, 2002; Meiran, Kessler, \& Adi-Japha, 2008), with the key distinguishing feature that resolution of the task-set is said to occur dynamically, in parallel with stimulus identification. However, Koch and Lavric (2020) and Monsell and McLaren (2020) suggest that TSR might be regarded as an incremental dynamic process, consistent with the PEP implementation. This view has been expressed in some recent discussions of TSR (e.g., Monsell, 2015, 2017). The initial assumptions of TSR are no longer tenable and the initial distinction between TSI and TSR has blurred. Indeed, Monsell and McLaren cite an explicit TSI model, Gilbert and Shallice (2002), as an example implementation of dynamic 
TSR. In this sense, we agree that more recent proposals about TSR are compatible with the PEP model functioning.

Monsell and McLaren (2020) further suggest that (re)configuration is the result rather than the process of changing task-sets. If the result of priming decision options via episodic retrieval is considered a (re)configuration of the task-set, then the PEP model could indeed be considered to (re)configure itself. But this also makes "reconfiguration" nearly theory neutral, consistent with a plethora of competing perspectives (but perhaps excluding the compound-cue retrieval notion in Schneider \& Logan, 2005). It is also somewhat ambiguous what exactly it means to call reconfiguration a result: it is neither a behaviour, nor a mental process. In any case, we do not seem to disagree with Koch and Lavric (2020) or Monsell and McLaren (2020) concerning what the PEP model does, only in what we should label said processes. Yet it is also important to stress that while we do similarly assume passive goal carryover in our model, this goal "inertia" is not the primary driving force of the switch cost or other observed effects in the modelled data (e.g., task-rule congruency effects).

\section{Future Modelling Efforts}

Some of the commentaries discuss future potential modelling goals of the PEP model. For example, Pfeuffer (2020) discusses potential broader extensions to the binding domain, exploring, for instance, stimulus-category and stimulus-response binding effects (e.g., Horner \& Henson, 2011; Moutsopoulou, Yang, Desantis, \& Waszak, 2015; Pfeuffer, Moutsopoulou, Pfister, Waszak, \& Kiesel, 2017), action-effect learning (e.g., Elsner \& Hommel, 2001, 2004), and the relation between short-term binding and long-term learning effects (e.g., Giesen, Schmidt, \& Rothermund, 2020; Moeller \& Frings, 2017a, 2017b; Schmidt, Giesen, \& Rothermund, 2020).

Koch and Lavric (2020) and Monsell and McLaren (2020) rightly point out that we did not simulate the reduction in switch cost (RISC) with increasing cue-target intervals (CTIs; e.g., Meiran, Chorev, \& Sapir, 2000). RISC has frequently figured into discussions of the relative explanatory power of TSR and TSI (Meiran, 1996; Monsell \& Mizon, 2006). Monsell and McLaren further indicate that we did not simulate the residual switch cost (Rogers \& Monsell, 1995): a smaller but non-zero switch cost with a long CTI, which suggests that anticipatory TSR or inertia has limits (i.e., is not successful in reconfiguring the task entirely before stimulus onset). We did not report simulations of RISC and residual switch costs, as our work suggests a new ambiguity in what reduces with longer CTIs. For instance, the RISC could be due to a reduction or elimination of binding effects with a longer CTI (e.g., see Frings, 2011; Moeller \& Frings, 2017a) and the "true" switch cost might not be reduced at all. Alternatively, it could be that the "true" switch cost is eliminated entirely, and the remaining "switch cost" is actually a "residual binding effect". Thus, it is unclear (for the moment) what an appropriate model fit would look like. With new participant data (e.g., a study like that in Schmidt \& Liefooghe, 2016, but with varied CTIs), we may be able to address these questions.

\section{Conclusions}

The PEP model presents a novel perspective on task switching. On the one hand, we do not argue against a role of executive processes on behaviour. We do, however, implement some of these executive processes in a less ambiguous (or "homuncular") fashion. Our work also highlights that these executive processes may not be directly responsible for many of the behavioural effects observed in task switching. Simpler binding biases, though already well-known, may have much more substantial influences on behaviour than previously assumed. We are encouraged by the interest shown in our work by the commentators and hope that future research will serve to fractionate the homunculus even further and to further explore binding and its relation to task switching.

\section{Ethics and Consent}

This article does not include any participant data and therefore did not require ethics approval or participant consent.

\section{Acknowledgements}

This research was supported by the French "Investissements d'Avenir" program, project ISITE-BFC (contract ANR15-IDEX-0003) to James R. Schmidt and Grant BOF16/MET_V/002 of Ghent University to Jan De Houwer. Correspondence concerning this article can be addressed to James R. Schmidt, Université de Bourgogne, LEAD-CNRS UMR 5022, Pôle AAFE, 11 Esplanade Erasme, 21000 Dijon, France.

\section{Competing Interests}

The author has no competing interests to declare. 


\section{References}

Allport, A., Styles, E. A., \& Hsieh, S. L. (1994). Shifting intentional set: Exploring the dynamic control of tasks. In C. Umiltà \& M. Moscovitch (Eds.), Attention and Performance XV (15th ed., pp. 421-452). Cambridge, MA: MIT Press.

Arrington, C. M., \& Logan, G. D. (2004). Episodic and semantic components of the compound-stimulus strategy in the explicit task-cuing procedure. Memory \& Cognition, 32, 965-978. DOI: https://doi. org/10.3758/BF03196874

Braem, S., Bugg, J. M., Schmidt, J. R., Crump, M. J. C., Weissman, D. H., Notebaert, W., \& Egner, T. (2019). Measuring adaptive control in conflict tasks. Trends in Cognitive Sciences, 23, 769-783. DOI: https://doi.org/10.1016/j.tics.2019.07.002

Dreisbach, G., Goschke, T., \& Haider, H. (2006). Implicit task sets in task switching? Journal of Experimental Psychology: Learning, Memory, and Cognition, 32, 1221-1233. DOI: https://doi.org/10.1037/02787393.32.6.1221

Dreisbach, G., Goschke, T., \& Haider, H. (2007). The role of task rules and stimulus-response mappings in the task switching paradigm. Psychological Research, 71, 383-392. DOI: https://doi.org/10.1007/ s00426-005-0041-3

Elsner, B., \& Hommel, B. (2001). Effect anticipation and action control. Journal of Experimental Psychology: Human Perception and Performance, 27, 229-240. DOI: https://doi.org/10.1037/0096-1523.27.1.229

Elsner, B., \& Hommel, B. (2004). Contiguity and contingency in action-effect learning. Psychological Research, 68, 138-154. DOI: https://doi.org/10.1007/s00426-003-0151-8

Forrest, C. L. D., Monsell, S., \& McLaren, I. P. L. (2014). Is performance in task-cuing experiments mediated by task set selection or associative compound retrieval? Journal of Experimental Psychology: Learning, Memory, and Cognition, 40, 1002-1024. DOI: https://doi.org/10.1037/a0035981

Frings, C. (2011). On the decay of distractor-response episodes. Experimental Psychology, 58, 125-131. DOI: https://doi.org/10.1027/1618-3169/a000077

Frings, C., Hommel, B., Koch, I., Rothermund, K., Dignath, D., Giesen, C., ... Philipp, A. (2020). Binding and Retrieval in Action Control (BRAC). Trends in Cognitive Sciences, 24, 375-387. DOI: https://doi. org/10.1016/j.tics.2020.02.004

Giesen, C., Schmidt, J. R., \& Rothermund, K. (2020). The law of recency: An episodic stimulus-response retrieval account of habit acquisition. Frontiers in Psychology, 10, Article 2927. DOI: https://doi. org/10.3389/fpsyg.2019.02927

Gilbert, S. J., \& Shallice, T. (2002). Task switching: A PDP model. Cognitive Psychology, 44, 297-337. DOI: https://doi.org/10.1006/cogp.2001.0770

Hommel, B., \& Colzato, L. S. (2015). Learning from history: The need for a synthetic approach to human cognition. Frontiers in Psychology, 6, Article 1435. DOI: https://doi.org/10.3389/fpsyg.2015.01435

Horner, A. J., \& Henson, R. N. (2011). Stimulus-response bindings code both abstract and specific representations of stimuli: Evidence from a classification priming design that reverses multiple levels of response representation. Memory \& Cognition, 39, 1457-1471. DOI: https://doi.org/10.3758/s13421-011-0118-8

Koch, I., \& Lavric, A. (2020). Has "erasing" made things clearer? Journal of Cognition, 3(1): 25, pp. 1-3. DOI: https://doi.org/10.5334/joc.111

Kramer, A. F., Cepeda, N. J., \& Cepeda, M. L. (2001). Methylphenidate effects on task-switching performance in attention-deficit/hyperactivity disorder. Journal of the American Academy of Child \& Adolescent Psychiatry, 40, 1277-1284. DOI: https://doi.org/10.1097/00004583-200111000-00007

Logan, G. D. (1990). Repetition priming and automaticity: Common underlying mechanisms? Cognitive Psychology, 22, 1-35. DOI: https://doi.org/10.1016/0010-0285(90)90002-L

Logan, G. D., \& Bundesen, C. (2003). Clever homunculus: Is there an endogenous act of control in the explicit task-cuing procedure? Journal of Experimental Psychology: Human Perception and Performance, 29, 575-599. DOI: https://doi.org/10.1037/0096-1523.29.3.575

Logan, G. D., \& Bundesen, C. (2004). Very clever homunculus: Compound stimulus strategies for the explicit task-cuing procedure. Psychonomic Bulletin \& Review, 11, 832-840. DOI: https://doi.org/10.3758/ BF03196709

Logan, G. D., \& Schneider, D. W. (2006). Priming or executive control? Associative priming of cue encoding increases "switch costs" in the explicit task-cuing procedure. Memory \& Cognition, 34, 1250-1259. DOI: https://doi.org/10.3758/BF03193269

Longman, C. S. (2020). A small platoon of idiots have been allowed to flourish, but the homunculus has not been erased from memory. Journal of Cognition, 3(1): 23, pp. 1-3. DOI: https://doi.org/10.5334/joc.106 
Longman, C. S., Lavric, A., \& Monsell, S. (2016). The coupling between spatial attention and other components of task-set: A task-switching investigation. Quarterly Journal of Experimental Psychology, 69, 2248-2275. DOI: https://doi.org/10.1080/17470218.2015.1115112

Longman, C. S., Lavric, A., \& Monsell, S. (2017). Self-paced preparation for a task switch eliminates attentional inertia but not the performance switch cost. Journal of Experimental Psychology: Learning, Memory, and Cognition, 43, 862-873. DOI: https://doi.org/10.1037/xlm0000347

Longman, C. S., Lavric, A., Munteanu, C., \& Monsell, S. (2014). Attentional inertia and delayed orienting of spatial attention in task-switching. Journal of Experimental Psychology: Human Perception and Performance, 40, 1580-1602. DOI: https://doi.org/10.1037/a0036552

Meiran, N. (1996). Reconfiguration of processing mode prior to task performance. Journal of Experimental Psychology: Learning, Memory, and Cognition, 22, 1423-1442. DOI: https://doi.org/10.1037/02787393.22.6.1423

Meiran, N. (2020). Simple control. Journal of Cognition, 3(1): 26, pp. 1-4. DOI: https://doi.org/10.5334/ joc. 107

Meiran, N., Chorev, Z., \& Sapir, A. (2000). Component processes in task switching. Cognitive Psychology, 41, 211-253. DOI: https://doi.org/10.1006/cogp.2000.0736

Meiran, N., Kessler, Y., \& Adi-Japha, E. (2008). Control by action representation and input selection (CARIS): A theoretical framework for task switching. Psychological Research, 72, 473-500. DOI: https:// doi.org/10.1007/s00426-008-0136-8

Meiran, N., Liefooghe, B., \& De Houwer, J. (2017). Powerful instructions: Automaticity without practice. Current Directions in Psychological Science, 26, 509-514. DOI: https://doi. org/10.1177/0963721417711638

Moeller, B., \& Frings, C. (2017a). Dissociation of binding and learning processes. Attention, Perception, \& Psychophysics, 79, 2590-2605. DOI: https://doi.org/10.3758/s13414-017-1393-7

Moeller, B., \& Frings, C. (2017b). Overlearned Responses Hinder S-R Binding. Journal of Experimental Psychology: Human Perception and Performance, 43, 1-5. DOI: https://doi.org/10.1037/xhp0000341

Monsell, S. (2015). Task-set control and task switching. In J. M. Fawcett, E. F. Risko, \& A. Kingstone (Eds.), The handbook of attention (pp. 139-172). Cambridge, MA: MIT Press.

Monsell, S. (2017). Task set regulation. In T. Egner (Ed.), The Wiley handbook of cognitive control (pp. 29-49). Chichester, UK: John Wiley \& Sons. DOI: https://doi.org/10.1002/9781118920497.ch2

Monsell, S., \& Driver, J. (2000). Banishing the control homunculus. In S. Monsell \& J. Driver (Eds.), Attention and Performance XVIII (pp. 3-32). Cambridge, UK: MIT Press.

Monsell, S., \& McLaren, I. (2020). PEP does not dispense with but implements task-set reconfiguration. Can it handle phenomena more diagnostic of endogenous control? Journal of Cognition, 3(1): 27, pp. 1-5. DOI: https://doi.org/10.5334/joc.109

Monsell, S., \& Mizon, G. A. (2006). Can the task-cuing paradigm measure an endogenous task-set reconfiguration process? Journal of Experimental Psychology: Human Perception and Performance, 32, 493-516. DOI: https://doi.org/10.1037/0096-1523.32.3.493

Mordkoff, J. T., \& Halterman, R. (2008). Feature integration without visual attention: Evidence from the correlated flankers task. Psychonomic Bulletin \& Review, 15, 385-389. DOI: https://doi.org/10.3758/PBR.15.2.385

Moutsopoulou, K., Yang, Q., Desantis, A., \& Waszak, F. (2015). Stimulus-classification and stimulus-action associations: Effects of repetition learning and durability. Quarterly Journal of Experimental Psychology, 68, 1744-1757. DOI: https://doi.org/10.1080/17470218.2014.984232

Pfeuffer, C. U. (2020). Item-specificity and intention in episodic memory. Journal of Cognition, 3(1): 24, pp. 1-4. DOI: https://doi.org/10.5334/joc.110

Pfeuffer, C. U., Moutsopoulou, K., Pfister, R., Waszak, F., \& Kiesel, A. (2017). The power of words: On item-specific stimulus-response associations formed in the absence of action. Journal of Experimental Psychology: Human Perception and Performance, 43, 328-347. DOI: https://doi.org/10.1037/xhp0000317

Rogers, R. D., \& Monsell, S. (1995). Costs of a predictable switch between simple cognitive tasks. Journal of Experimental Psychology: General, 124, 207-231. DOI: https://doi.org/10.1037/0096-3445.124.2.207

Schmidt, J. R., Giesen, C., \& Rothermund, K. (2020). Contingency learning as binding? Testing an exemplar view of the colour-word contingency learning effect. Quarterly Journal of Experimental Psychology, 73, 739-761. DOI: https://doi.org/10.1177/1747021820906397

Schmidt, J. R., \& Liefooghe, B. (2016). Feature integration and task switching: Diminished switch costs after controlling for stimulus, response, and cue repetitions. Plos One, 11, e0151188. DOI: https://doi. org/10.1371/journal.pone.0151188 
Schmidt, J. R., Liefooghe, B., \& De Houwer, J. (2020). An episodic model of task switching effects: Erasing the homunculus from memory. Journal of Cognition, 3(1): 22, pp. 1-38. DOI: https://doi.org/10.5334/ joc.97

Schneider, D. W., \& Logan, G. D. (2005). Modeling task switching without switching tasks: A short-term priming account of explicitly cued performance. Journal of Experimental Psychology: General, 134, 343367. DOI: https://doi.org/10.1037/0096-3445.134.3.343

Verbruggen, F., McLaren, I. P. L., \& Chambers, C. D. (2014). Banishing the control homunculi in studies of action control and behavior change. Perspectives on Psychological Science, 9, 497-524. DOI: https://doi. org/10.1177/1745691614526414

How to cite this article: Schmidt, J. R., Liefooghe, B., \& De Houwer, J. 2020 Erasing the Homunculus as an Ongoing Mission: A Reply to the Commentaries. Journal of Cognition, 3(1): 28, pp. 1-6. DOl: https://doi.org/10.5334/ joc.117

Submitted: 21 July 2020 Accepted: 24 July 2020 Published: 10 September 2020

Copyright: (c) 2020 The Author(s). This is an open-access article distributed under the terms of the Creative Commons Attribution 4.0 International License (CC-BY 4.0), which permits unrestricted use, distribution, and reproduction in any medium, provided the original author and source are credited. See http://creativecommons.org/ licenses/by/4.0\%

] $\mathbf{u}[$ Journal of Cognition is a peer-reviewed open access journal published by Ubiquity OPEN ACCESS $\precsim$ 